LA EMERGENCIA DEL CONTROL NORTEAMERICANO SOBRE LA ECONOMIA PERUIANA: 1850-1930

POr: HERACLIO BONILLA

Serie: Documentos de Trabajo

Noviembre, 1975

$\mathrm{N}^{\circ} 28$

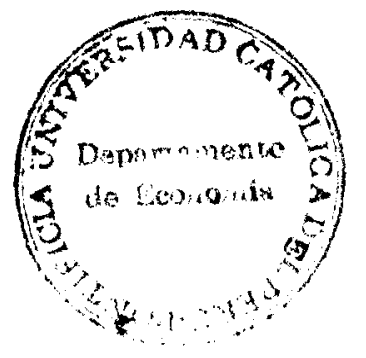


LA EMERGENCIA DEL CONTROL NORTEAIIERICANO SOBPE

LA ECONOMIA PERUANA: $1850-1930$

Heraclio Bonilla*

A nadie escapa el peso decisivo que tiene la presencia norteamericana en la estructura interna y en el destino del continente latinoamericano. La naturaleza de este contacto, así como sus consecuencias, no siempre fueron las mismas: ellas dependieron de los cambios producidos al interior de los Estados Unidos y de Latinomérica, así como de la posi -ciớn de ambos continentes dentro del sistema de relaciones internacionales. Pero pese a la importancia que desde comienzos de.siglo tiene Estados -Unidos para el continente latinoamericano, sólo en la última década los científicos sociales empiezan a formular con rigor las cuestiones más per tinentes. Esta toma de conciencia es sin duda un sintoma de la crisis de estas relaciones,. Estos estudios, sin embargo, básicamente enfocan los aspectos más controvertidos de las relaciones contemporáneas y donde, ade más, no existe una preocupación nayor por situarlos en una perspectiva -histórica.

Este ensayo, por ello mismo, tiene un doble propósito: tomando la experiencia de las relaciones peruano-norteamericanas, se trata de establecer la cronología de la naturaleza de estas relaciones y, además, de mostrar los mecanismos de emergencia del control norteamericano sobre el Perú. Más que un ensayo definitivo, es apenas un intento de precisar, en una perspectiva histórica, algunos de los problemas inheréntes a estas re

* E1 autor es miembro del Instituto de Estudios Peruanos y profesor en e1 Departamento de Economía de la Universidad Católica de Lima. 
laciones y la pertinencia del examen de los mismos. Su limitación deriva también del hecho de que este anälisis estâ integralmente basado en los documentos diplomáticos norteamericanos y en algunos estudios que existen sobre las relaciones peruano-norteamericanas.

Estados Unidos y o1 Perr. E1 Contexto del Siglo XIX

Hablar del siglo XIX en e1 Perú es básicamente hablax del guano $y$ de Inglaterra. Entre 1840 y 1880, las cuatro décadas decisivas de 1a historia económica del Perí en el siglo XIX, 1a economía peruana depen dió en efecto de la explotación del abono conservado en las is as del 1itoral costeño. La gran potencia industrial inglesa, por otra yarte, ejer ció el control indiscutido pero no absoluto de esta economía a través de los mecanî́smos de comercializaciôn y de financiaciớn.

Pero al interior del espacio dominado por Gran Bretaña, otras potencias europeas como Francia, Alemania, y más tarde Italia, tuvieron también cierta importancia en el control del mercado peruano $y$, sobre todo; en la captación de sus excedente:s. Un papel similin, en este lado -del Atlántico, correspondió a los Estados Unidos de Norteamérica. Vếamos sus características.

Entre 1840 y 1858 el Perú exportó aproximadamente $3 ' 277,302$ to neladas de guano, de las cuales cerca de un quinto fueron para el mercado norteamericano, via Baltimore, mientras que los cuatro quintos restantes se destinaron al mercado europeo, principalmente britânico. ㅌ En esta eta pa fue particularmente importante 1854, en el que Barreda Hnos., temeroso de perder la consignación, envió a los Estados Unidos 159,654 toneladas-'. Es importante destacar, por otra parte, que si bien é. mercado norteameri cano no tuvo la misma importancia que el mercado británico pare 1a coloca ción del abono peruano, sin embargo los veleros americanos ociparon una posición predominante en el transporte del guano a todos los mercados de1 mundo . 
Desde fines de 1a década del 50 el volumen de exportación del guano a Estados Unidos empieza a declinar sensiblemente. La acumulación de considerables stocks de guano en el mercado norteamericano, la política de precios del Gobiemo peruano y la competencia presentada por otros fertilizantes, fueron los mayores determinantes de este declive. La guerra de Secesiớn de los Estados Unidos (1860-1865) consolida esta crisis y cierra el mercado norteamericano a las exportaciones del abono peruano 3 /. Además, al terminarse la guerra de Crimea, los veleros ingleses y franceses se encontraban libres para competir con los norteamericanos en el transpor te del guano. Después de la guerra norteamericana, finalmente, la exporta ción del guano con destino a ese país no llegó a recuperar sus niveles anteriores por la aguda competencia ofrecida por otros abonos. E1 cuadro si guiente muestra las oscilaciones de la exportación del guano peruano a Ios Estados Unidos de Norteamérica:

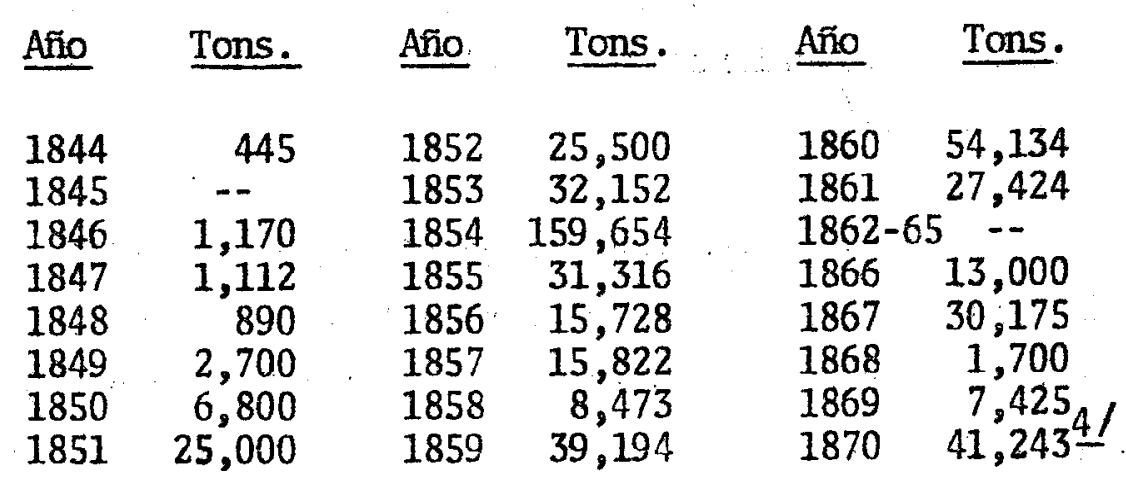

Conjuntamente con el guano, que era el producto doninante, las exportaciones peruanas con destino a los Estados Unidos comprendian tam -biên, aunque en valores ínfimos, plata, lana de varios tipos, cueros, or-chilla, azácar, Peruvian bark y vinos y licores. Recíprocamente, hasta la década del 70 del siglo pasado, las exportaciones americanas con destino al Perí consistían en algodones gruesos, lanas manufacturadas, vestidos, botas y zapatos, comestibles, sedas, muebles, quincallería, pertrechos navales, vinos y licores, drogas y medicinas, maderas y hielo. Dos trata-dos comerciales, suscritos en 1851 y 1870 , regularon el comercio peruano norteamericano durante el siglo XIX. 
Louis Nolan, en un trabajo pionero sobre las relaciones comer ciales entre Estados Unidos y el Perí, ha tratado de medir la significa-ción económica de este intercambio. E1 comenta que entre 1825 y 1850 el comercio fue insignificante, con un saldo desfavorable a los Estados Unidos. Esta tendencia cambió sensiblemente a partir de 1850. Así, mien -tras que entre 1841-1851 el valor global de este intercambio ascendía a: 3'775,611 dólares, dejando una balanza comercial desfavorable a los Estados Unidos del orden de 2'163,449 dólares, entre 1851-1861 el valor del comercio fue de $11^{\prime} 287,601$ dólares, esta vez con un saldo favorabie a 10 s Estados Unidos de 2'636,635 dólares: -51 incremento del comercio y del saldo positivo a favor de los Estados unidos se hacen mucho más evidentes en la década siguiente, pese a los efectos negativos pero relativamente cortos que tuvo la guerra civil americana. Entre 1861-1871 el valor fue de 23'042,522 dolares, más del doble de la década precedente, y entre ...1871-1875 de $32^{\prime} 422,366$ dólares. En este último quinquenio, este inter-cambio representó una balanza comercial favorable a los Estados Unidos de $11 ' 992,232$ dб1ares. 6 !

Otro de los aspectos característicos del tráfico comercial en tre Estados Unidos y el Perí se refiere a 1a pesca de ballenas. Hasta 1850 , en efecto, los puertos norteños del litoral peruano, particularmente Tumbes, fueron continuamente visitados por veleros norteamericanos quie nes venían a la búsqueda de aceite y huesos de ballena. Incluso el artícu 1o XII del tratado comercial de 1851 fue destinado a fortalecer este tráfi $\mathrm{CO}$, al permitir que las embarcaciones norteamericanas estuviesen dispensa das del pago de los derechos de aduana y fuesen permitidos vender y com-prar mercancias libremente hasta por un valor de mil dolares. II pero tambiên aquí la guerra civil americana, asociada al desplazamiento de las ba Ilenas hacia el Articn, puso término a esta actividad.

El Cónsul Card informó a este respecto que en 1861 sólo ancla ron en el puerto de Tumbes 83 barcos norteamericanos; en 1852, 42; en .1863,25 y en 1864 probablemente $10.9 /$ 
La década del 70 del siglo pasado en el Pexú corresponde al gran ciclo de la expansión ferroviaria. Su implantación fue en realidad una conquista de la fracción más moderna de la clase dirigente, quien intentó así atemuar el despilfarro impuesto por otros Gobiernos de los considerables recursos generados por la explotación del guano. La ferroviarización del país, al igual que la imigración, correspondieron también a las exigencias de una ideología que veía en cllas los mecanismos más adecuados para superar los obstáculos al crecimiento económico del país. Una vez más, Gran Bretaña y en menor grado Europa, constituyeron las fuen tes del capital necesario a la construcción de las líneas férreas, a través de diversos préstamos al Estado peruano. Pero el material requerido para 1a construcción ferroviaria provino principalmente de 1os Estados -Unidos. Entre 1850 y 1870 ocurrió también el restablecimiento de la economía agrícola del litoral costeño, centrado en la producción del algodón y del azúcar y en respuesta a las demandas del mercado externo. Tal desa rrollo requirió el eqüipamiento de estas haciendas con maquinarias agríco las, rubro en el cual el concurso de los Estados Unidos fue igualmente im portante. 9 / Entre 1871 y 1880 , en síntesis, el valor del intercambio en-tre Estados Unidos y el Perá ascendio a 36'590,058 dólares, es decir más de un $40 \%$ sobre el valor de la década precedente.

E1 cuadro siguiente, elaborado por Nolan, muestra los valores anuales de este intercambio entre 1865-1880: 
Año

1865

1866

1867

1868

1869

1870

1871

1872

1873

1874

1875

1876

1877

1878

1879

1880

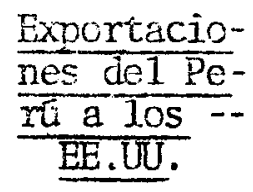

$\$$

250,815

807,238

1'701,987

1'765,397

1'381,310

2'557,833

4.731,430

$1 \cdot 668,983$

1'186,161

1'256,286

$1 ' 291,235$

$1 \cdot 426,043$

1'479,511

$1^{\circ} 531,591$

1. 857,859

361,308
Importacio-

nes de 105

EE.UU. 21-

Perú

$\Phi$

781,386

1'215,835

1'730,914

$1^{\prime} 666,355$

$1^{\prime} 673,445$

1'974,167

$2^{\prime} 381,005$

4'595,403

2'864,945

1'914,871

$2^{\circ} 480,941$

$1 \cdot 032,898$

$1 ' 300,552$

$1^{\prime} 005,538$

$1^{\circ} 305,362$

918,136

Saldo

$-530,571$

$-408,597$

$-28,927$

$+98,042$

$-287,135$

$+583,666$

$+21530,425$

$-2 \cdot 926,420$

$-1^{\prime} 678,784$

$-658,585$

$-1 ! 189,706$

$+393,145$

$+178,959$

$+525,953$

$+552,497$

$-556,82810 /$

E1 valor de. importaciones procedentes de los Estados Unidos desde la década del 70 se incrementa aun-más si se incnrpora el valoride los metales preciosos renitidos al Perú. Según Nolan, entre 1870 y 1874 estos fueron los siguientes:

\begin{tabular}{cc} 
Añ & \multicolumn{1}{|}{} \\
1870 & $1^{\prime} 819,018$ \\
1871 & $1^{\prime} 200,000$ \\
1872 & $4^{\prime} 500,000$ \\
1873 & $1^{\prime} 549,099$ \\
1874 & 707,035
\end{tabular}

Paralelamente a la intensificación del trăfico comercial durante la década del 70 , se dieron también cambios importantes en la natu raleza de este intercambio. Del lado de las exportaciones peruanas, por ejemplo, el guano progresivamente pierde su posición dominante en favor - 
de las creciente importaciones del salitre. Pero es a nivel de las importaciones norteamericmas que se produjeron las nodificaciones más signifipativas, en el sentido de que 1a importaciōn de bienes durables y de capital empezaron a:superar en la década de1 70 las irportaciones de bienes de consumo. El cuadro siguiente mestra la composición de estas importaciones entre 1871 y. 1875 .

$\underline{1871} \quad \underline{1872} \quad \underline{1873} \quad \underline{1874} \quad \underline{1875}$

Hierro; acero $\quad 561,699 \quad 1 ' 374,407: 623,028 \quad 417,789 \quad 1 ' 105,357$ y productos.

Lana y productos de lana. $506,726 \quad 1^{\prime} 003,203 \quad 491,783 \quad 337,550 \quad 411,962$

Comestibles 144,007 371,676 381,076 241,923 169,260

Aceites, minerales y refina dos.

104,923

$$
90,736
$$

67,952

60,506

103,993

Drogas, tintes y productos químicos.

$91,203 \quad 46,897 \quad 57,113 \quad 56,409 \quad 27,851$ 피

En síntesis, la ferroviarización del país obtenida por el concurso de los capitales británicos y mediante la hipoteca del guano, 1levó a un importante desarrollo del intercambio camercial peruano-norteamerica no. Pero pese a este fortalecimiento el control del conjunto del comer-cio peruano siguio siendo ejercido por Inglaterra. Este hecho indiscutible fue la consecuencia de la dependencia financiera del Perú respecto a Inglaterra, de los elevados fletes de transporte por la ruta del Atlántio y del control de las rutas oceánicas que ejerció Inglaterra a través de sus líneas de navegación a vapor 2 ! . A 0110 debe añadirse un sistema interno de comercialización enteramente en poder de ingleses, franceses alemanes e italianos, quienes por su ligazón con mercaderes e industria-les europeos tendían naturalmente a fortalecer el intercambio con Ingla-terra y Europa 13 ! Pese a ello Ta temprana presencia de 1os Estados Unidos posibilitố la apertura de las vías necesarias para el establecimiento de su posterior hegemonía. 
La 1lamada Guerra del Pacifico entre Perú y Chile (1879-1884) cierra uramäticamente el ciclo del guamo en la vida económica del Perá.Eila genera, además la casi total destrucción del potencial productivo del pais. La reconstrucción de le post-gucrra fue posible por un cambio sensible en la naturaleza de las inversiones extranjeras, que de préstamos al Estado peruano devienen en colucaciones directas en las âreas mäs importantes de materias primas, $y$ por la fusión y monopolización interna de los recursos productivos, particularmente tierras y minerales.

Es este contexto el que prepara el ascenso de 1a hegemonía -norteamericana en el control de la economía peruana, a través del progre sivo desplazamiento de Inglaterra y de las otras potencias europeas. Es te drástico canbio de 1a posición del Perú dentro del mercado internacio nal fue también el resultado de la modificaciốn en las relaciones de fuer za entre Inglaterra y Estados Unidos es decir el declive del poderío britảnico por la obsolescencia de su estructura tecnológica.

En 1880, en plene guerra con Chile, las exportaciones peruanas con destino a Estados Unidos ascendieron a solamente 758,000 dólares y -las importaciones procedentes de aquel país a 94,000 dólares 14 ! Este -brusco descenso en el nivel del intercambio comercial entre Estados Unidos y el Perú, en relaciôn a la década y media anterior, perduró hasta 1898. En este año las exportaciones del Peri a lns Estados Unidos ascienden a 1'112,100 dolares y las importaciones a 876,900 dólares $15 /$ La recupera- ciớn del tráfico comercial peruano-norteamericano, preludio de una intensificación mucho mayor desde el alba del presente siglo, fue el resultado de dos factores combinados: por una parte, el fortalecimiento de $1 \varepsilon$ estruc tura interna del Perú $y$, por otra, el establecimiento desde 1894 de dos líneas de vapor (en reemplazo de los vetustos veleros previos) que mensual mente ligaron Nueva York con la costa oeste de América del Sur.

Los inicios de la Dominación Norteamericana

Es el año de 1900 que señala el comienzo del desarrollo espec tacular del intercembio comercial entre Estados Unidos y el Peru, al ascen der las exportaciones peruanas a 4'640,796 dólares y las importáciones de 
Estadọ Uunidos a I'447,472 dólares. Este ascenso, además, generô importan tantes cambios en la estructura del comercio peruano. Hasta la guerra con Chile las exportaciones peruanas al continente europeo representaron cerca de un $80 \%$ del total, mientras que el mercado norteamericano absorbía solamente un $2 \%$ de1 total de las exportaciones peruanas 17!. Las importaciones norteamericanas, por otra parte, representaron en 1877 un $7 \%$ del total de

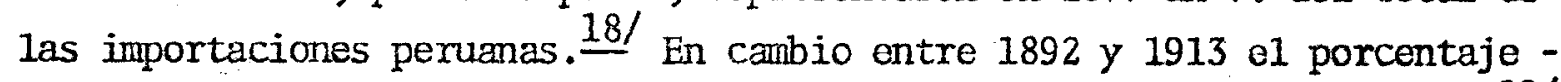
de las importaciones peruanas de Estados Unidos pasa de un $7.1 \%$ a $29.8 \%$ 19/, mientras que el porcentaje de las exportaciones peruanas asciende de un $2.7 \%$ en 1877 , a cerca de un $33 \%$ del total en 1913. 20/

Si se observa las cifras de los valores anuales del movimiento de exportación e importación entre los Estados Unidos y el Pera, particular mente entre 1903 y 1905 (ver cuadro del anexo), se constata que las importa ciones de Estados Unidos superaron 1as exportaciones. Este es un hecho sig nificativo, porque quiere decir que la hegenonia norteamericana se consolidó por el establecimiento de los primeros grandes enclaves imperialistas de dicados a la explotación del cobre, del petróleo y del azácar. De uni con-trol parcial del mercado peruano, los Estados Unidos a través de crecientes inversiones directas de capital y de la formación de las primeras corpora-ciones gigantes, iniciaron pues desde la primera década del presente siglo el sometimiento del conjunto de la economía peruma. La instalación de estas empresas norteamericanas no sólo explica la absorción creciente de bienes de capital procedentes de los Estados Unidos, sinó también el porque de la articulación eficaz entre la producción de materias prinas y el mercado norteamericano. Es, en suna, en respresta a las exigencias del Imperio que abedece la particular naturaleza hel tráfico conercial con e1 Perá. Por ejemplo entre 1895 y 1899 las ventas americanas de rieles, carros y trenes representaron un valor amual de 16,300 dólares monto que 1lega a 192,800 dó lares anuales entre 1901 y 1905.211

Es tambiên la exportación de bienes de capital norteamericano (bienes de hierro y acero) que constituyó la base fundamental de 1a de -rrota británica y alemana en la competencia por el control de la economia 
peruana. El cuadro siguiente muestra el incremento diferencial en la exportación de estos bienes entre Estados Unidos, Inglaterra y Alemania:

\begin{tabular}{|c|c|c|c|}
\hline & \multicolumn{2}{|c|}{ Por año } & \multirow[t]{2}{*}{ Incremento } \\
\hline & \multicolumn{2}{|c|}{ (miles de dólares) } & \\
\hline & $1895-1899$ & $1900-1904$ & $\underline{9}$ \\
\hline $\begin{array}{l}\text { Estados Unidos } \\
\text { Inglaterra } \\
\text { Alemania\& }\end{array}$ & $\begin{array}{l}269 \\
636 \\
155\end{array}$ & $\begin{array}{r}810 \\
1,092 \\
317\end{array}$ & $\begin{array}{l}201.1 \\
71.7 \\
104.522\end{array}$ \\
\hline
\end{tabular}

$\mathrm{La}$ inexistencia de una banca norteamericana que financiara las actividades de industriales y comerciantes impidió que el intercambio peruano-norteamericano pudiese alcanzar mayores proporciones. Si, por ejem plo, un fabricante o un exportador recurría 2 un banco en Nueva York para. descontar una letra girada por un cliente sudamericano, el banco podia -aceptar o rechazar el pedido en función de la solvencia del industrial o de1 comerciante exportador, puesto que desconocía la situación del cliente en Sudamérica. Para sortear estas dificultades los empresarios nortea mericanos adoptaron el sistcna "cash against documents".

Tal sistema protegía los intereses de los industriales norteamericanos que ignoraban las condiciones de América del Sur, pero no excluía enteramente los créditos en la exportación de sus bienes. Las casas mercantiles o los comerciantes consignatarios en Plueva York eran loes encargados de pagar al contado a los empresarios, al mismo tiempo que recupera ban estos capitales por el descuento de las letras giradas por sus clientes en América del Sur. Los bancos europeos que operaban en Latinoamérica, así como los bancos norteamericanos (después de la promulgación del Federal Reserve Act) constituyeron un mercado eficiente para estas operaciones de descuento. En adelanto, entonces, la aceptación de un documento crediticio no dependía más de la solvencia del cliente sino de 1a repu

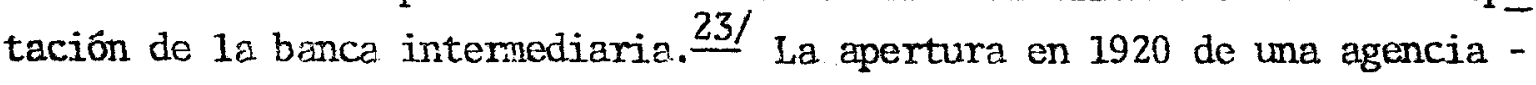
del National City Bank of New York Lima, al permitir una financiación mucho mảs directa, terminó por consolidar la supremacía norteamericana en - 
el comercio internacional del Perú.

Los Efactos de 1a Primera Guerra Mundial

La posición predominante adquirida por los Estados Unidos en el controi de la economía peruana durante la primera década del presente siglo se consolida en el curso de la Primera Guerra Mundial. Y esta conso lidación fue paralela a un mayor fortalecimiento de la economía peruana co mo consecuencia de la gran demanda de materias primas por parte de los paí ses en conflicto. Un indicio de esta situación puede encontrarse en el de sarrollo espectacular de1 comercio internacional del Perú entre 1915 y 1917:

\begin{tabular}{|c|c|c|c|}
\hline Año & $\begin{array}{l}\text { Importacio- } \\
\text { nes peruanas }\end{array}$ & $\begin{array}{l}\text { Exportacio- } \\
\text { nes feruanas }\end{array}$ & Saldo \\
\hline & Le. & Ip. & \\
\hline $\begin{array}{l}1912 \\
1913 \\
1914 \\
1915 \\
1916 \\
1917\end{array}$ & $\begin{array}{r}5 \cdot 140,338 \\
6 \cdot 088,776 \\
4 \cdot 827,930 \\
3 \cdot 095,544 \\
8^{\prime} 683,150 \\
15 \cdot 502,851\end{array}$ & $\begin{array}{r}9 \cdot 438,581 \\
9 \cdot 137,780 \\
8 \cdot 767,790 \\
11 \cdot 521,807 \\
16.541,063 \\
15^{\prime} 643,114\end{array}$ & $\begin{array}{l}4^{\prime} 298,243 \\
3 \cdot 049,004 \\
3 \cdot 939,860 \\
8^{\prime} 426,263 \\
7 \cdot 957,913 \\
5 \cdot 140,563\end{array}$ \\
\hline
\end{tabular}

Poro el impacto de la gueria no fue untomático ni inmediato. En los primeros meses del conflicto se prołujo ina completa desorganiza- ción àel comercio intemacional de los países de la costa oeste de la Amé rica del sur, asociado a una crisis financiera y a una caída de los tipos de cambio de su moneda. Fue a partir de 1915 que la economía de estos -países empezó a fortalecerse al increnentarse la demanda de cobre, nitrato, estanio y algodón. Al restablecer esta demanida los anteriores niveles de precios, 1a exportaciốn de estos productos creció en cantidad y en va1or. En el caso del Perú su situación fue aun mâs favorable puesto que el mercado de uno de sus importantes productos de exportación, el azúcar, no se debilitó con las perturbaciones iniciales de 1 a guerra: 
La gran demanda de las materias primas del Perd, por otra parte, gcneró una balanza comercial muy favorable, reforzéndose el tipo de su intercambio monetario. El $1^{\circ}$ de agosto de 1919 la libra peruena fue cotizada en Nueva York a 5.30 doleres; a fines de 1920 este tipo había declinado a solamente 4.74 dolares. $25 /$ El nivel de las importaciones, on cambio, no se incrementó en volumen por la crisis de los ccononias de los paises beli grantes. Puesto que los ingreses del Gobierno dependían on gran parte de los irmuestos a la importación, sus rentas no fucron pues tan importantes como las de las empresas o casas comerciales privadas. $26 /$

La guerra, como se scñaló anteriomonte, acentuó 1a hegemonía norteamericane sobre la economía peruana. En efecto, on 1913 las importa ciones norteamericanas representaron un $28.8^{\circ}$ de1 total de las importacio nes peruanas, mientras que el mercado norteamericano absorbía un $33.2 \%$-del total de les exportaciones peruanas. El porcentaje de las importacio nes se elevó a un $54.3_{y}^{\circ}$ en 1918 y a un $46.5 \%$ y a un $61.9 \%$ en 1919 , mientras que para los mismos años, las exportaciones peruanas a Estados Unidos ascen dieron $a$ un $46.5 \%$. El audro siguiente indica los valores correspondientes a estas exportaciones.

\begin{tabular}{|c|c|c|}
\hline \multirow[t]{2}{*}{ f } & $\frac{\frac{\text { Exportaciones }}{\text { deIPera }}}{\text { EE.UU. }}$ & $\frac{\frac{\text { Importaciones }}{\text { deI Perad de }}}{\text { U. UU. }}$ \\
\hline & $\Phi$ & $\$$ \\
\hline 1913 & $14^{\circ} 761,355$ & $8: 541,934$ \\
\hline 1914 & 14827,700 & $7^{\prime} 643,928$ \\
\hline 17015 & $25 \cdot 054,360$ & $7^{9} 107,102$ \\
\hline 19 & $50: 024,370$ & 24699,126 \\
\hline 70 & $54^{\circ} 609,063$ & 438864,096 \\
\hline 19 & $48^{\circ} 944 ; 071$ & $27,772,373$ \\
\hline
\end{tabular}

En estos años las exportaciones norteamericanas al Perú consis ticron on nanufacturas de: hjerro y acero, productos de algcdón, madera, productos químicos, bienes cléctricos, automóviles, carne, carbón e irmple mentos agrícolus, mientras que ol cobre fue el principal producto de expor teción dol Perú a los Estados Unidos, seguido por el algodón, lanas, cauchos, aceites y minerales y azicar. 27 ! 
Se señaló .qu la exportación de este tipo de materias primas -fue la que provocô el fortaleciniento de la economía peruana durante 1a -Primera Guerra Mizdial. Pero, wa vez más, este fortalecimiento al depender de una ccymtura aterna mu favorable no podía ser sino muy precario. Al igual que en el sigjo KIX eI estimulo al crecimiento fue totalmente externo a la econonía peruana, sin que se produjesen efectos inducidos que posibilitasen un desarrollo de un mayor alcance.

Si se toman los tres productos más importantes que el Perú expor tó entre 1914 y 1918, es decir el cobre, el azúcar, y e:1 algodón es posi-ble encontrar, en efecto, una correlac ón nuy estrecha entre los niveles de precios en el mercacio internacional y las oscilaciones en la producción y exportación de los mismos. El cuadro siguiente muestra las fluctuacio-nes de los precios cotizados on ima del cobre "standard", por tonelada $y$ en libras esterlinas, entre 1912 y 1918 :

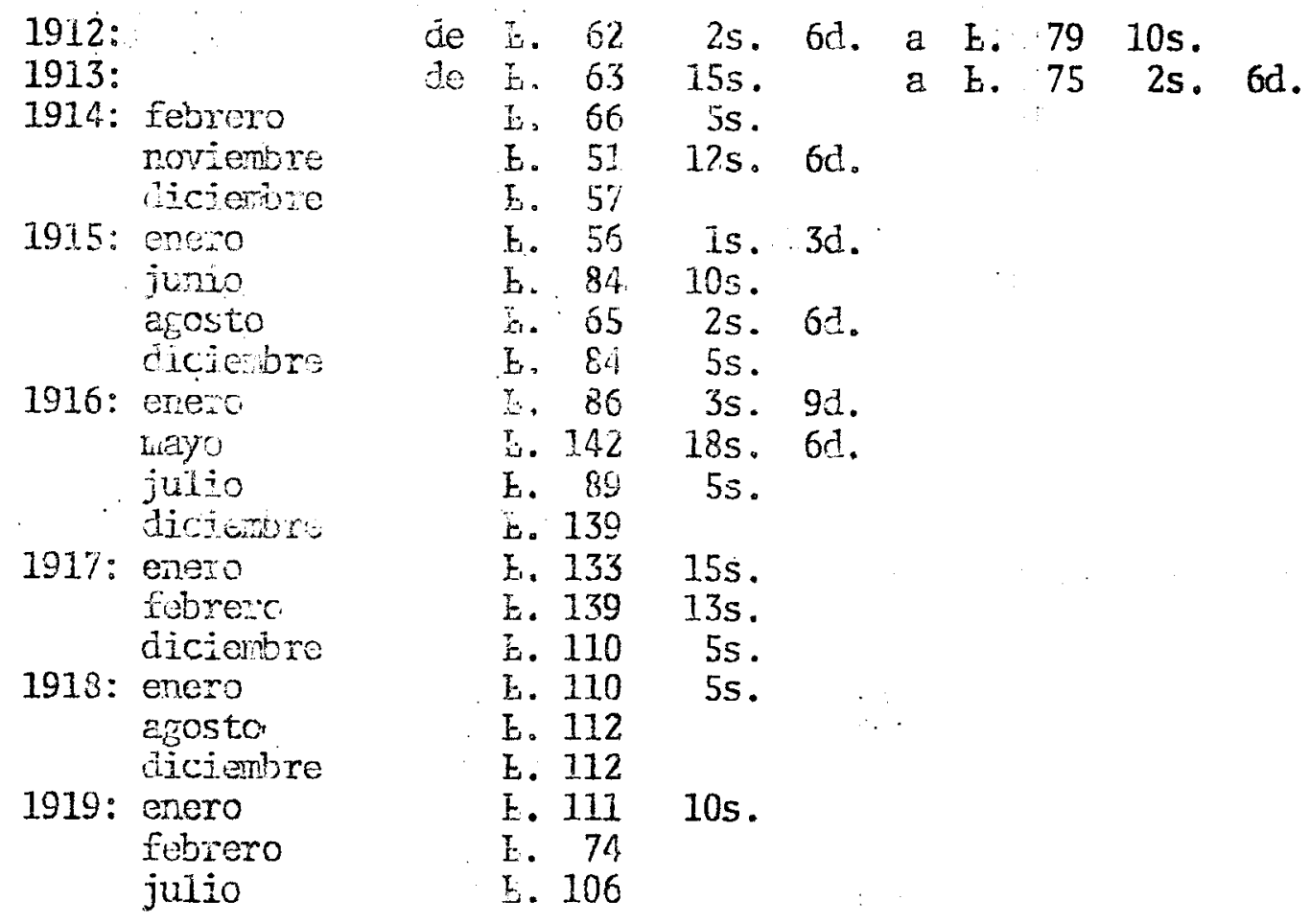

Las fluctuaciones de la lemanda del cobre configuraron el ci clo de exportación del cobze, e.t culi fuc exportado ontro 1912 y 1917 -- 
los volúmenes siguientes:

$\begin{array}{ll}\text { Año } & \frac{\text { Tons. mët. }}{34,830} \\ 1912 & 41,316 \\ 1913 & 29,440 \\ 1915 & 41,015 \\ 1916 & 52,338 \\ 1917 & 49,99928\end{array}$

E1 azúcar, por otra parte, fue export ado fundamentalmente a 1os Estado Unidos y a Inglaterra y en menor medida a Chile, Uruguny y Argenti na y los volumenes de su comercialización siguieron tmbiên estrechamente las fluctuaciones del precio del azicar en el mercado internacional. Los precios por cada quintal de azticar en libras esterlinus cotizados en 1a Bolsa de Londres fueron:

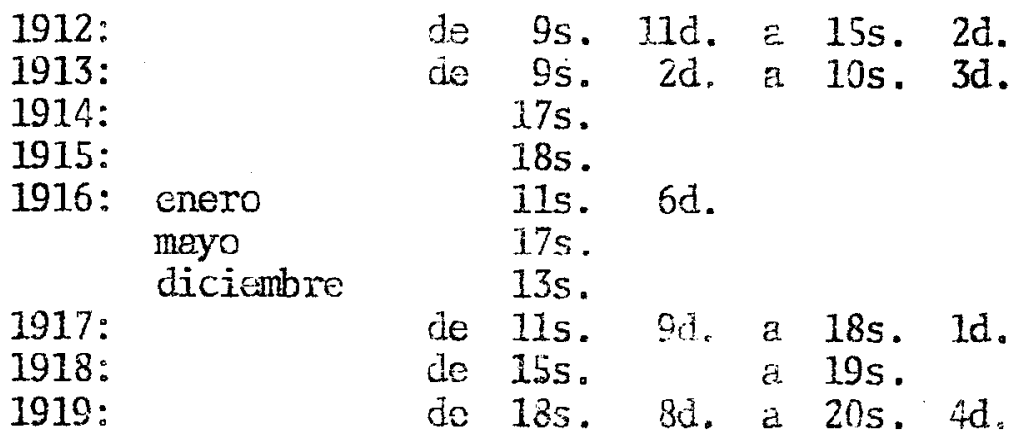

Entre 1912 y 1917, por otra parte, so exportaron las siguien-tes toneladas mêtricas de azúcar:

1912

1913

1914

1915

1916

1917
147,710

142,901

176,671

220,257

239,009

212,041 
Si se considera que la producción total del aztacer peruana fue en:

$\begin{array}{ll}\text { Año } & \text { tons.mét. } \\ 1916-17 & 216,000 \\ 1917-18 & 265,000 \\ 1918-19 & 250,000\end{array}$

resulta que sólo el 15 o̊ del total praducido era para el consuno interno 29.

Antes de la guerra prâcticamente la totaliủad del ajgodôn permano exportado se remitía a Liverpool y desde ahs era reexporticio, en perte, a los Estados Unidos. Pero la guerra hizo que los expresarios norteameri canos comprasen el algodôn directarente en el Perú, a fin de satisfacer rápidamente la demanda de pertrechos de guerra. El inicio del conflicto, por otra parte, tuvo más bien efectos negativos soive la demanda del aloo dón peruano por 1a acumulaciôn de grandes stocks de aigodôn no vendidos en los Estados Unidos y por las dificuliades de transporte para una mer-cancía que requería grandes velumeres de especio en les barcos. La corsi guiente caida de los precios provocó que el algodón no fuese sarbrado en varias haciendas del litoral en 1914. Pero el desarrollo de la guerra -cambió favorablementc esta situación desde fines de 1915, al rismo tieipo que estimulaba la producción del algoión de fibra 1arga, más que el de fi bra corta.

E1 Liverpool Cotton Exchange clasificó el ágodón neruano en -cuatro clases: áspero, semi-áspero, suave o Esypto y el Mitafifi y Peruvian sea Island. Las oscilaciones de sus precios dependieron de las cotizaciones en Liverpool; entre 1913 y 1919 los precics proredio por cada libra de algodón de estas cuatro clases, en peniques, fueron los siguientes: 


\begin{tabular}{|c|c|c|c|c|c|c|}
\hline Afio & Aspero & Semj-äspero & \multicolumn{2}{|c|}{ Suave o Erypto } & \multicolumn{2}{|c|}{$\begin{array}{l}\text { Pernivian Sea } \\
\text { Island }\end{array}$} \\
\hline $\begin{array}{l}1913 \\
1914 \\
1915 \\
1916 \\
1917 \\
1918\end{array}$ & $\begin{array}{rll}10.25 & \text { a } & 9 . \\
9 . & \text { a } & 8.75 \\
8.75 & \text { a } 11.50 \\
11.50 & \text { a } 18 . \\
18 . & \text { a } & 32 . \\
33 & \text { a } & 37 \\
36 & \text { a } & 29.75\end{array}$ & 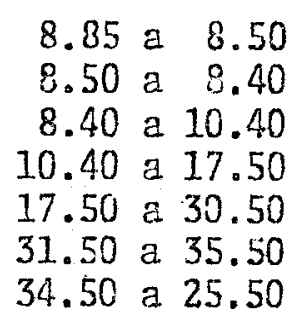 & $\begin{array}{r}8.20 \mathrm{a} \\
7.61 \mathrm{a} \\
5.50 \mathrm{a} \\
8.88 \mathrm{a} \\
12.06 \mathrm{a} \\
27.07 \mathrm{a} \\
25.80 \mathrm{a}\end{array}$ & $\begin{array}{r}7.84 \\
5.30 \\
8.54 \\
12.20 \\
25.13 \\
2.05 \\
27.04\end{array}$ & $\begin{array}{l}11 \\
10.50 \\
3.50 \\
10.50 \\
24 . \\
34 . \\
33 .\end{array}$ & 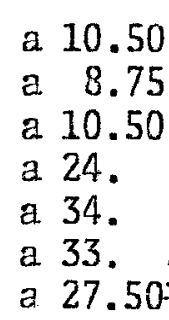 \\
\hline
\end{tabular}

E1 incipiente desarrollo de 1 a inđustria textil peruana requirió el consumo de aproximadamente 5 mil tonelajas de algodón por año, procediên dose a la exportación del saldo de la producción. Entre 1912 y 1917 se exportaron los siguientes volúmenes:

\begin{tabular}{|c|c|c|c|c|}
\hline Año & Aspero & $\frac{\text { Semi-â:;- }}{\text { pero }}$ & Stuave & $\frac{\text { Peruyian }}{\text { Sea Isiand }}$ \\
\hline T.m. & T.m. & …… & T. & T. Iil \\
\hline $\begin{array}{l}1912 \\
1913 \\
1914 \\
1915 \\
1916 \\
1917\end{array}$ & $\begin{array}{c}-\ldots . . \\
703 \\
5,436 \\
1,994\end{array}$ & $\begin{array}{l}7,492 \\
7,240 \\
4,429 \\
5,348 \\
1,625 \\
1,22,5\end{array}$ & $\begin{array}{r}10,995 \\
14,924 \\
16,267 \\
12,539 \\
13,375 \\
7,328\end{array}$ & $\begin{array}{r}555 \\
1,597 \\
2,670 \\
2,635 \\
3,654 \\
6,658 \mathrm{y} /\end{array}$ \\
\hline
\end{tabular}

La consolidacjón de la hegenonía nortearexicune, por otxa, parte, implicó cambios sustantivos en la posiciói de la econonía peruana dentro del mercado internacional, es decir su alejaniento del ảrea de influen cia y control de las potencias curopeas. Entre 1910 y 1912 Gran Bxetaña figuraba en el primer rango de los paîses que dxrovisionaban el mercado pe ruano, seguido por los Estados Inidos, Alemania y Francia. En 1513, un año antes de la guerra, cerca de la tercera parte de las importaciones británicas consistian en textiles de todo tipo, al mismo tiempo que Gran -Bretaña suministraba cerca de la mitad de tolo el carbón irportado en el Pera. E1 saldio de las importaciones británicas, finalmente, oscruro cons-tituído por una gran variedad de bienes menufacturados, cntre los clales se encontraban hierro corrugado, boribas hidralulicas, irplmontos agricoles, 
cables y productos quimicos. La guerra al cerrar las fuentes britanicas de abasteciniento, al incrementar los costos de trasporte y al diversificar el intercambic en nuevos canales generó el eclipse de Gran Bretaña en relación al Pera. Il alajro siguiente mestra la posición ce Gran Bretana $y$ de los otros paises curopeos en el comercio de irportación del Perú entre 1910 y 1913 :

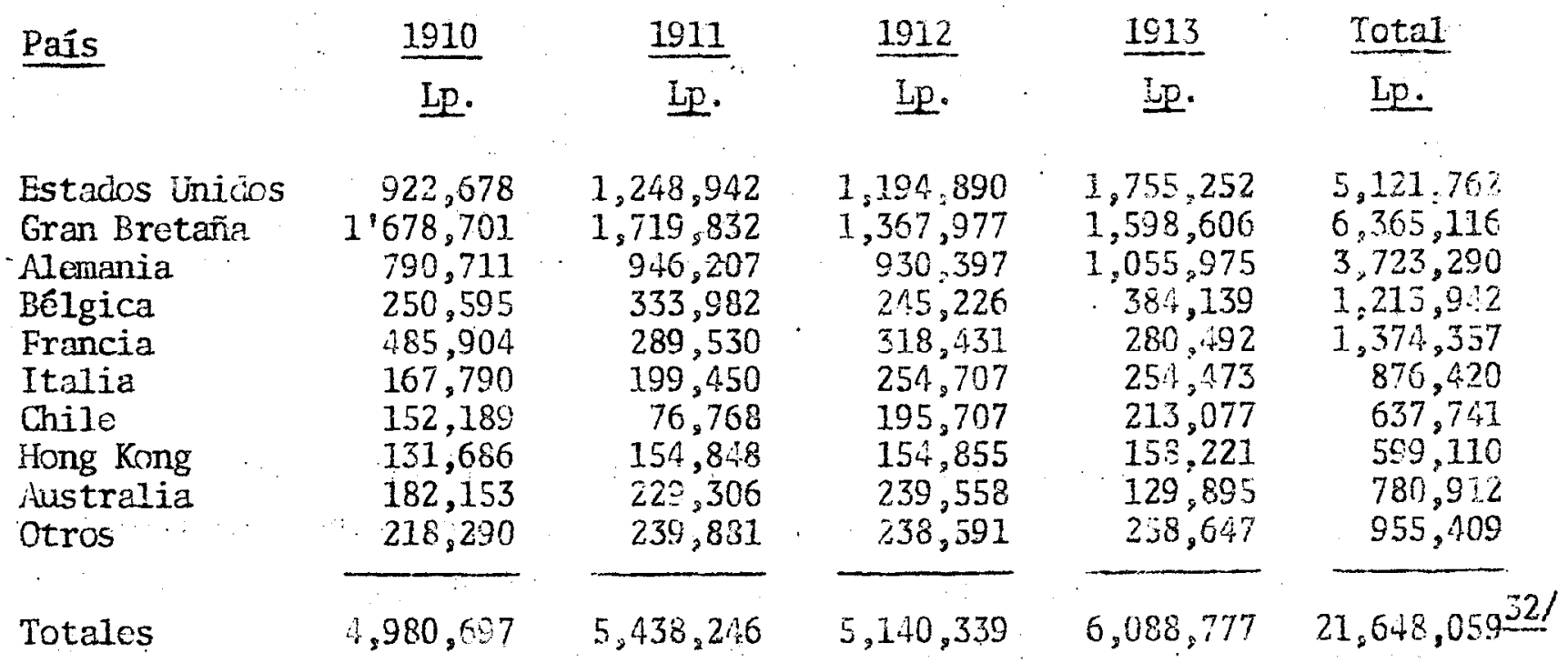

Desde 1913 y on 105 arios le $2 a$ guerra fie que Estados Unibos des plazô a Inglaterra en el liderazgo rel comercio de inportación ied Perfi: Do hecho entre 1912 y 1917 ol val de las impoxtaciones norteanericantes on el Perí fue tres voces más que ol vajor to las inpertacinnes britanicas." Alemania y Bélgica, que tenian antes ic 12 guerra ma posición relevante ên el comercio intcrnacional perumo, desaparecen le este fiaro y pasan a ser reemplazaios pox España, las Indias Británicas, Japón e Itaiia. Un 50 de las exportacimes españolas al Perú 10 constitúan los textiles y el saldc era de artículos alinknticios. Prácticamonto la totalicad de las importacio nes de las Inuias Britänicas consistían an saces de yute para los metales y el azúáar, mientras que el Japón remitía principalmente textiles $y$, en me. nor medida, arroz, papel y lccería. El cuachs siguicnte muestra el radio de estas importaciones entre 1914 y 1917 : 


\begin{tabular}{|c|c|c|c|c|c|}
\hline Pais & $\frac{1914}{\text { Lp. }}$ & $\frac{1915}{\operatorname{Lp} .}$ & $\frac{1916}{L D .}$ & $\frac{1917}{\mathrm{Lo} .}$ & $\frac{\text { TotaI }}{\text { Lia }}$ \\
\hline Estarios Inidos & $\frac{2 \mathrm{~L} .}{570.724}$ & LP. & $\frac{\text { LP. }}{5.710 .587}$ & 노. & LE: \\
\hline Gran Bretaña. & $1,338,552$ & $\begin{array}{r}1,488,264 \\
662,546\end{array}$ & $.1,496,305$ & $1,934,666$ & $\begin{array}{r}10,906,200 \\
5,432,069\end{array}$ \\
\hline Hong Kong & 129,274 & 181,947 & 301,914 & 453,762 & $1,066,397$ \\
\hline España & 62,547 & 45,233 & 170,119 & 357,621 & 635,520 \\
\hline Chile & 89,618 & 94,390 & 298,768 & 357,255 & 840,032 \\
\hline Inclia Británica & 55,755 & 87,409 & 233,174 & 350,024 & 726,362 \\
\hline Italia & 201,632 & 157,831 & 237,248 & 248,707 & 845,418 \\
\hline Australia & 187,088 & 12,373 & 235,417 & 231,942 & 666.820 \\
\hline Francia & 155,974 & 89,067 & 195,265 & 225,280 & 666,586 \\
\hline Japón & 12,462 & 18,383 & 85,499 & 129,496 & 245,840 \\
\hline Otros & $1,024,304$ & 258,102 & 311,859 & 431,387 & $2,015,652$ \\
\hline Totales & $4,827,930$ & $3,095,545$ & $8,683,150$ & $13,502,851$ & \\
\hline
\end{tabular}

Finalmonte, a 1os efectos que turvo la primera Guerra Mandial en la consolicación de la hegemonía americana en el Peră, deben añadirse aque-$110 s$ derivados de la aperture del Canal de Panamá en agosto de 1914. Para el intercambio comercial entro Ios Estados Unilos y los puertos de 1a costa del Pacifico, el Cana? de Panamá significs fundamentalmente la recucción de las distanci s y el abaratamiento de los costos do transporte. Ambos hechos incidieron pesitivanente en una intensificación en la circulación de las mow cancías y en une scnsible ratucción en sus precios firalos de venta. A cra. vés del Canal de Penanâa el viaje de Nueva York al Cailao so redujo a solarion te doce dias, mientras que las jistancias ahoriades fueron las siguientes (en millas)

$$
\frac{\text { De }}{\text { Nueva }} \frac{\text { De }}{\text { York }} \frac{\text { De }}{\text { Drleans }} \frac{\text { De }}{\text { Diver- }}
$$

A] Cal13o:

Por el Estrecho do Magallanes. $9,613 \quad 10,029 \quad 9,980 \quad 11,057$

Por el Cánal de

Panamá.

$\begin{array}{lllll}\text { Panamá. } & \frac{3,363}{6,250} & \frac{2,784}{7,245} & \frac{5,937}{4,043} & \frac{7,730}{3,327.34}\end{array}$ 
Las Relaciones Comerciales Entre Estajos Unidos y el Pera de 1a Post-guerra a la Crisis del 29

El térnino de la guerra puso también fin a una excepcional co-yuntura que permitió el desarrollo de la econoría de exportación peruana y el fortalecimiento del tráfico peruano-norteamericaro. Entre 1920 y 1921 el valor de las exportaciones peruanas con destino a los Estados Unides cae de $74^{\prime} 656,809$ a $14^{\prime} 733,000$ ' 161 ares, miertras que $e 1$ valor de las impor taciones de Estados Unidos al Perá baja de 46'675,710 a 24'028,00 tólares. La contracciôn del mercado externo tivo efectos negativos no sólo entre lus grupos ligados al comercio internacional, sinó que incidió tambièn en las finanzas del Estado peruano al reducirse drásticamente los ingresos deriva dos de 1 a importaciôn.

De agosto de 1922 a 1929, sin embargo, Ias exportaciones perua nas se restablecen nuevamente por una creciente punción de capitales norteamericanos en los sectores ligados al comercio exterior y por los aitos precios de venta del azúcar. $36 /$ Esta recuperación; enpero, no llegó a los niveles alcanzacios durante 1a Primera Guerra Mandial. Como promedio, el valor anual del comercio entre estrios unizos y el Ferí entre 1922 y 1929 , osciló alredecor de los 40 milllones de jólares. Pú una expensiôn además atravesada por cortas recesiones crmo 12 de 1923, 1925 y 1926", las que se debieron a crisis estacionales, caíla de los precios del algolón y desajustes en el mercado monetario interno.

En estos años el algodón, el cobre, el azúcar, y en grado creciente el petróleo constituyeron las principales mercancías exportadas -desde el Perú. E1 peso específico de cada una de ellas dentro de este co mercio puede observarse el siguiente cuadro: 


\begin{tabular}{|c|c|c|c|c|c|c|}
\hline Año & Azúcar & Algodón & Caucho & Lana & Petróleo & Cobre \\
\hline & $\frac{0}{3}$. & $\underline{\underline{g}}$ & $\underline{\underline{g}}$ & $\stackrel{\circ}{6}$ & $\frac{8}{0}$ & $\frac{O}{1}$ \\
\hline 1922 & 24 & 25 & 1 & 3 & 22 & 18 \\
\hline 1923 & 27 & 22 & 1 & 3 & 18 & 17 \\
\hline 1924 & 21 & 22 & 1 & 4 & 23 & 14 \\
\hline 1925 & 11 & 32 & 1 & 4 & 24 & 18 \\
\hline 1926 & 17 & 22 & $\overline{1}$ & 3 & 28 & 16 \\
\hline 1927 & 16 & 23 & 1 & 3 & 27 & 18 \\
\hline 1928 & 13 & 21 & - & 4 & 28 & 20 \\
\hline 1929 & 12 & 18 & - & 4 & 30 & 23 \\
\hline 1930 & 11 & 18 & - & 3 & 30 & $19 \underline{38}$ \\
\hline
\end{tabular}

Dado que el mercado norteamericano era ya el más importante para la colocación de las materias primas peruanas, el algodón, el azúcar, el cobre y el petróleo figuraron tambiên entre las principales exportacio nes del Perú a los Estados Unidos. Los bienes de capital y alimentos y be bidas, por otra parte, constituían los principales rubros importados por el Perú desde los Estados Unidos.

En resumen, 10 que interesa relevar aquí es el hecho que duran te la guerra, y los años de recuperación de la post-guerra, las corpora-ciones norteamericanas establecidas en el Perá desde comienzos del sig1o XX 1legaron a una consolidaciôn efectiva de su posición. Por consiguiente fueron estas empresas las principales beneficiarias en la expansión de las exportaciones peruanas. La Cerro de Pasco Copper Corporation, por ejemplo, fue la segunda empresa exportadora (después de la International Petroleun Conpany) en la década de 1os 20. El valor de sus exportaciones entre 1920 y 1930 totalizó cerca de 212 millones de dolares (54 millones de libras peruanas), es decir alrededor de1 $20 \%$ del valor total de las ex portaciones. La Northern Perú, asimismo, exportó en este mismo período por un valor de 9 millones de libras peruanas, cerca del $3 \%$ del total de

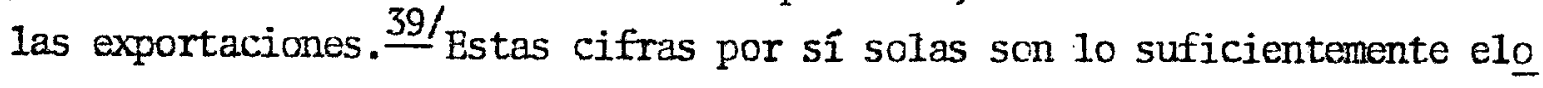
asentes para mostral el rol de las cmpresas norteamericanas en el control de la economía peruana. 
Durante todo ol siglo pasado el control ejercido por Gran Breta ña sobre $1 \mathrm{a}$ economía peruana fue fundamentalmente comercial y financiero. Es decir, que además del sometimiento del mercado peruano a las necesidades de la producción inglesa, la economía peruaria fue considerada desde 1a Independencia como un área propicia a la colocación de los capitales británicos. Hasta el comienzo de la Guerra del Pacífico la exportación de estos capitales desde Inglaterra se dió bajo la forma de reiterados préstamos a un Estado peruano pernanente hambruna monetaria. La fragilidad de la estructura productiva, asi como la casi permanente bancarrota del Estado peruano, generaron al mismo tiempo, una colosal acumulación de la deuda externa y una bajísima rentabilidad de estos capitales inverti-dos.

E1 témino de la guerra inicia un nuevo ciclo en la naturaleza de ias inversiones británicas, el cual fue una consecuencia de cambios profundos tanto en la economía peruana como en la economía británica. E1 11 amado contrato Grace, en efecto, cancela la deurla externa contraída por el Perú con los acreedores británicos mediante 1a entrega del guano, de los ferrocarriles, de tierra en el Perené $y$ del control de la navegaciôn lacustre en el Titicaca; además, las nuevas inversiones británicas se orientan ahora hacia colocaciones directas en el comercio, servicios $y$ algunos de los sectores productivos.

Hasta los inicios del presente siglo el total de las inversio nes británicas directas ascendió a 27 millenes do dólares, los cuales como se acaba de scinalar, estuvicron colocados fundamentalmente en fe-rrocarriles, servicios y on media docena de empresas orientadas al mercado interno. Desde 1900 hasta 1930 la Lobitos Oilfields (petróleo), - 1a Duncan Fos Co. (algodón) y, en menor escala, e1 Sayapullo Syndicate y la Lampa Mining Company (minerales), fueron las únicas empresas brita nicas caya producción estuvo orientada al mercado externo. Empresas co 
mo 12. Loncion and Pacific Petrolem, la British Sugar Company y otras plan taciones azucareres con Tra importante participación del capital inglés. fueron compradas en este forích por las nuevas empresas nortednericanas. Esto explica porque hasta comienzos de siglo sćlo el 5\% lol total de las exportaciones perunas fueron protucicas vor empresas extranjeras; de -1900 a 1930 , en cambio, la creciente implantación le las copresas nortea mericanas en las áreas jo proúcción ce materias frimas hizo que el $50 \%$ del total ie las exportaciones fuesen producicias por estas empreses. $\frac{40 /}{4}$

La hegemenía que Gran Bretaña ejerció curante todo el siglo -XIX sobro la econcmía peruana no posibilitó un desarmilo significativo de las inversiones directes norteamericares durante toda esta centuria.Con la excepción le pequeñas inversiones en la agricultura y minería por norteamericanos residentes en el Perú, "Cartavic" -adquirida por Grace Hnos. en 1882- era la unice emprese nortemoricana importante. 41/ Pero a partir de 1901, y sobre todo al etenerse la exportacion lo los capita los europeos jiranto $1 \mathrm{a}$ Primera Cuerre $\frac{12 /}{2}$ fluje de las inversiones nor teamericanas fue caja vez nés creciente. I1 riumo de oste crecimiento esturc ostruchononte ascoinco al estableciniento y a ia consoliación le las prineras corporaciones norteamericanos. He aqui algunas ce las fe chas significativas: 1901, necimiento de la Cerro de Pasco Copper Corporati.n; 1903, expmsion de Grace inos. a la intustria textil; 1907, apa rición le la Vanadiun C $c$; 1913, conpra le la Lonan and Pacific Petrolaum Co. por una subsiliaria de le Staniar Cil: 1915, estibieciniento en Lima de1 Benco Mercantil Americano por la Gulranty Trust, Brown -Brothers an. J.W. Seligman ce Nueva York; 1920, aperture de une agencia del National City Bank le Nueva York; 1921, creación de la Northern Perú Wining and Sheiting Co. por la American Smelting and Refining Co. $\frac{43 /}{\mathrm{B}}$ cuadro siguiente muestra el ritmo ie crecimiento de las inversiones di-rectas norteamericanas comparadas con las de Gran Bretaña: 


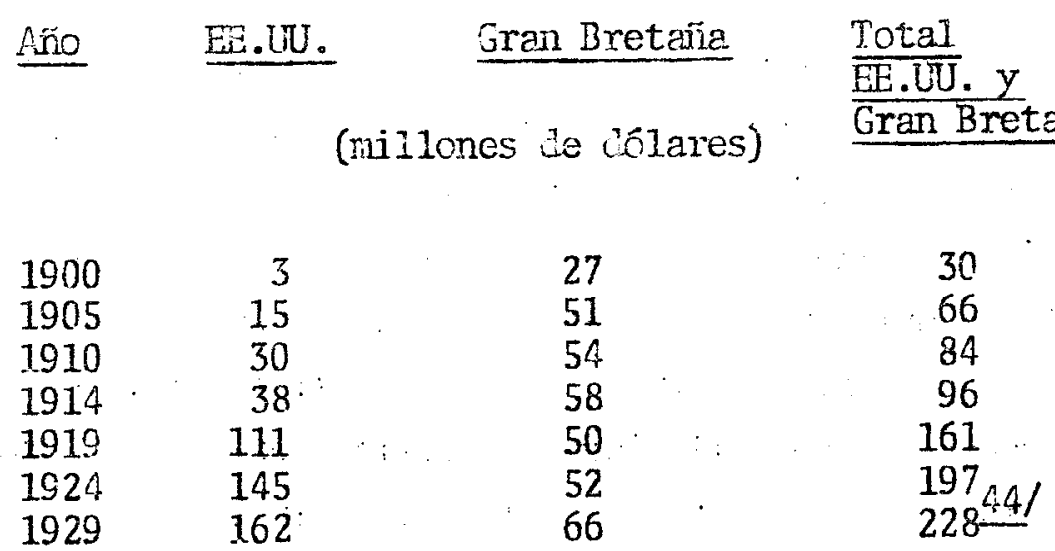

Lo fundamental de estas inversiones norteamericanas estuvo con centrado en el desarrcilo de la explotación minera, a través de las opera ciónes de empresas crmo la Cerro de Pasco Copper Corporation, la International Petroleum Company, la Vanadium Corporation of America, la Inca -Mining Company, la Northern Perú Vining and Smelting Company y en la adju dicación de los yacimientos de Cerro verce a la Anaconda. En menór esca. 1a, sin embargc, otros sectores de la economía peruana fueron también penetracios por estas inversiones iniciales. Es el caso de W.R. Grace and Co., en la procucción texil y de la pequeña industria; de Wes̉se1, Duval and Co., Pan American-Grace Airways, All America Cables y Frederick Snare Corporation, en el comercio y comunicaciones; la fred $T$. Lèy and Co. $y$ la Foundation $\mathrm{C} s$, en la construcción; la J. W. Seligman and $\mathrm{Co}$, , Ia Guaranty. Trust Co. de Nueva York y la National City Co., en el sector financiero.

El control del mercado interno peruano, por otra parte, se iden tificó durante el pexícdo 1900-1930 al ser reemplazado el viejo sistema de consignación de las mercancias norteamericanas por las ventas directas, a través de agencias, realizadas por las principales firmas norteamericanas. A finales del siglo XIX sólo la Singer Sewing Machine habia adoptado tal sistema, pero en las dos primeras décadas del presente siglo la United -States Steel Corporation, la Gourock Ropework Expcrt Company Ltd., la. -National, Paper and Type $C 0$., la Ingerso11-Rand $46 /$ expandieron sus ventas con la apertura en el perú de agencias directamente dependientes de 1a -. fima matriz. 
Las inversiones norteanericanas, finalnente, encontraron on e1 sector publico otxa de las áreas iriportantes para su colocación, sobre todo a través de üiversos préstamos efectuados durante la administración de Augusto P. Leguíe (1919-1930). Debe recr rdarse, a esto respecto, que e1 nacimiento de la Peruvian Corporation on 1890 había cancelado la cuantiosa deude acurnulacia por el Estado peruano curante el siglo XIX. Un empréstito suscrito en Aicmania por 600 mil libras esterlinas en 1906, a cambio de la hipoteca de los ingresos del Estanco de la SaI, reinicia en el siglo XX un muevo ciclo de la deuda externa del Pera. 47/ Pero es durante el "oncenio" de Leguía cuando se da un mayor incremento de la dependencia financiera -de1 Estado Peruano. Es así que mientras ol gasto fublico ascenlia 6'600,000 libras peruanas en 1919, en 1928 éste era de 25'700,000 1ibras. peruanas, incremento que fue financiado por el recurso a los préstamos nor teamericanos. In 1919 el 5\% ciel total del gasto público fue cubierto por este tipo de operaciones, porcentaje que en 1926 llega a un $43 \%$, mientras que en 1927-1928 el $56 \%$ del gastc público es financiado por los créditos externos. $18 /$ Esta prodigalidad creliticia permitió a Leguia cesarrollar una impresionante política de construcción le obras pablicas, asociado a una no menos inpresionante política de corrunción pública, en la busqueda de consolidación de su clientela polftica. El cuadro siguiente mustra los principales anréstitos suscritos por Leguía y los Bancos asociados a: su financiación: 
25.

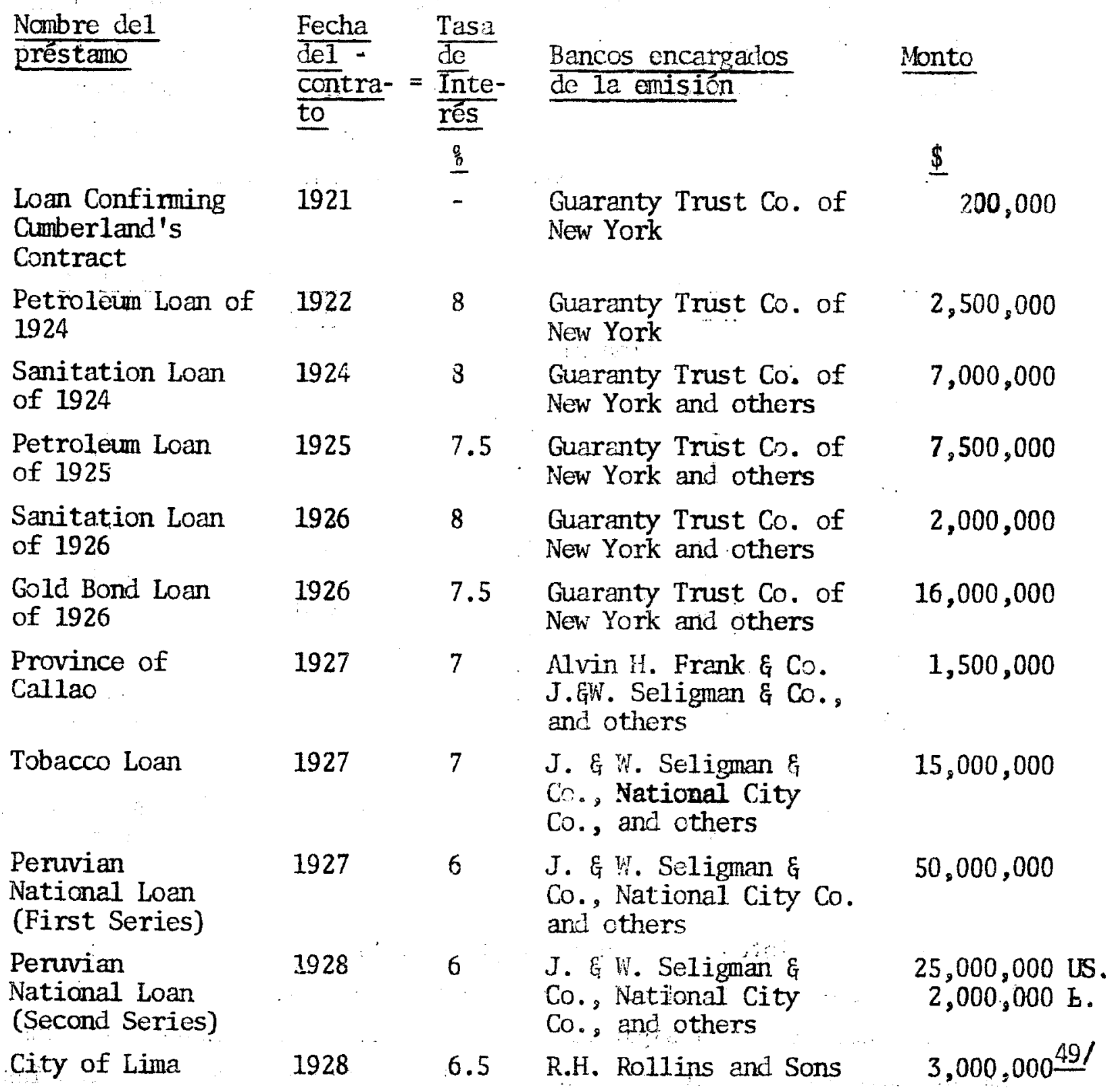


E1 resultado cie todas estas operaciones fue el total endeuda-miento del Estado peruano, proceso que, una vez más, termina con el colapso financiero y econónico de 1 Perú al cerrarse las fuentes externas de crê dito como consecuencia de la gran crisis de 1929. El cuadro siguiente indica el moviniento de la deuda externa de1 Pera entre 1919 y 1930:

\begin{tabular}{|c|c|c|c|c|}
\hline Año & $\frac{\text { Deuda en }}{\text { US } \$}$ & $\frac{\text { Deuda en }}{\underline{b}}$ & $\frac{\text { Deuda en }}{\text { US } \$}$ & $\frac{\text { Daula } \mathrm{cm}}{\mathrm{E} .}$ \\
\hline & (mi & & & \\
\hline 1919 & - & $1.0^{b}$ & $\because$ & - \\
\hline 20 & - & $1.0_{2}^{b}$ & - & - \\
\hline 321 & - & $0.9^{b}$ & - & -0.1 \\
\hline 1922 & 2.4 & 2.7 & 2.4 & 1.8 \\
\hline 1923 & 2.1 & 3.4 & -0.3 & 0.7 \\
\hline 1924 & 8.8 & 3.3 & 6.7 & -0.1 \\
\hline 1925 & 13.5 & 3.2 & 4.7 & $-0^{\prime} 1$ \\
\hline 1926 & 30.5 & 3.1 & 17.0 & $-0 . \overline{1}$ \\
\hline 927 & $66.4^{\mathrm{a}}$ & 3.0 & 35.9 & -0.1 \\
\hline 1928 & 90.7 & 4.9 & 24.3 & 1.9 \\
\hline 192 & 89.7 & 3.6 & -1.0 & $-1.3_{50}$ \\
\hline 1930 & 88.5 & 3.5 & -1.2 & $-0.1=$ \\
\hline
\end{tabular}

a. Excluílo bonos por un valor de 29 millones de b. Al 30 de junic. (de retiro.

En sintesis, el proceso que paulatinamente confuce a los -Estados Unidos al control hegemónico sobre la economía poriana comienza en la segunda mitad del siglo XIX. En sus inicios este control fue bási camente comercial, es decir a traves de la penetración de las mercancías norteamericanas en todos los intersticios dejados por la masiva exportación británica, proceso que se incrementa sensiblemente al demandar 1a ferroviarización del país la importación de los Estados Lnidos de crecien tes cantidades de material rojante. La guerre del Pacífico, el establecimiento de la navegación a vapor, las actividarles financieras te W.R. Grace, perniten la apertura de los primeros canciles para una incipiente inversión de los capitales norteamericanos. Pero es el establecimiento 
de los primeros enclaves agro-mineros; bajo el control directo de grandes empresas norteamericanas, el que llevará a una definitiva subordinación de la economía peruana a las exigencias de la expansión industrial americana. La Primera Guerra Mundial consolida este proceso, al mismo tiempo que pone término al control que las potencias europeas, principalmente In g1aterra, ejercían sobre la economía peruana desde los inicios del siglo XIX. La persistente demanda de crédit-s para un Estado bajo el control de una administración corrupta, así como cambios operados en las: formas de comercialización norteamericana; someterän también al control norteame ricano el sector financiero del Perá y harán más completa y más eficiente el daminio sobre su mercado interno.

Pero el establecimiento de esta hegemonía no fue sólo el re-sultado de mecanismos económicos y de mercado. La apertura de mercados, la implantac-ón de las empresas norteamericanas en los sectores productivos del país, 1a búsqueda de términos favorables en estas concesiones, fue ron posibles por la decidida intervención del Departamento de Estado norteamericano a través de sus principales agentes diplamáticos. La Electric Boat Company, el National City Bank of New York, la All American Cables son ejomplos de algunas de las empresas norteamericanas que contaron con el apoyo de su gobierno en el inicio o en el fortalecimiento de sus opera ciones en el Perrí. 


\section{- Anexo -}

Exportación e Importación entre EE.UU. y Peru

(Valor en dolares)

\begin{tabular}{|c|c|c|c|c|}
\hline Añio & $\begin{array}{c}\text { Exioraciôn } \\
\text { de1 Perú } \\
\text { US }\end{array}$ & 8 & $\begin{array}{c}\text { Importación } \\
\text { del Perú } \\
\text { US } \$\end{array}$ & $\frac{0}{6}$ \\
\hline & & & & \\
\hline 1891 & 206,010 & 2 & 980,992 & 10 \\
\hline 1892 & 674,181 & 6 & 636,813 & 7 \\
\hline 1893 & 535,097 & 5 & 493,324 & 7 \\
\hline 1894 & 499,902 & 6 & 395,438 & 6 \\
\hline 1895 & 836,476 & 11 & $\ldots$ & - \\
\hline 1896 & 768,778 & 7 & 999,380 & 12 \\
\hline 1897 & 636,428 & 4 & 752,919 & 9 \\
\hline 1899 & $1^{\prime} 212,400$ & 8 & 876,900 & 10 \\
\hline 1899 & $2^{\prime} 418,869$ & 16 & $I^{\prime} 026,057$ & 10 \\
\hline 1900 & $4^{\prime} 640,796$ & 21 & $1^{\prime} 447,472$ & 12 \\
\hline 1901 & $4^{\circ} 393,905$ & 20 & $2^{\prime} 099,104$ & 15 \\
\hline 1902 & $3^{\prime} 383,193$ & 18 & 28878,690 & 17 \\
\hline 1903 & $2^{\prime} 395,592$ & 12 & $3^{\prime} 767,195$ & 20 \\
\hline 1904 & $1^{1900,003}$ & 9 & $3 \cdot 795,743$ & 17 \\
\hline 1965 & $2^{8} 635,773$ & 9 & $3^{7} 462,974$ & 16 \\
\hline 1906 & $3120 \leq 480$ & 11 & $5^{i} 541,157$ & 22 \\
\hline 1907 & $7^{\prime} 848,152$ & 28 & $5: 751,996$ & 21 \\
\hline 1908 & $7 \cdot 053,936$ & 30 & $6.868,132$ & 26 \\
\hline 1909 & $7^{\prime} 278,445$ & 23 & 48117,673 & 19 \\
\hline 1910 & $9^{\prime} 878,327$ & 28 & $4 \cdot 484,214$ & 18 \\
\hline 1911 & $10^{\prime} 187,998$ & 28 & $6^{\circ} 082,352$ & 22 \\
\hline 1912 & $14^{\prime} 473,293$ & 31 & $5^{8} 763,423$ & 11 \\
\hline 1913 & $14^{\prime} 76 i, 355$ & 33 & $8^{\prime} 541,934$ & 28 \\
\hline 1914 & $14^{\prime} 827,700$ & 34 & $7^{\prime} 643,928$ & 32 \\
\hline 1915 & $25^{\prime} 054,360$ & 45 & $7^{\prime} 187,102$ & 48 \\
\hline 1916 & $50^{4} 024,370$ & 62 & $24^{\circ} 699,126$ & 58 \\
\hline 1917 & $54^{\prime}, 009,063$ & 58 & $43^{\prime} 864,096$ & 65 \\
\hline 1918 & $48^{\prime} 944.071$ & 46 & $27^{\prime} 772,373$ & 54 \\
\hline 1919 & $61^{8} 540,344$ & 46 & $37^{\prime} 226,688$ & 62 \\
\hline 1920 & $74: 656,309$ & 46 & $46^{\circ} 675,710$ & 55 \\
\hline 1921 & $14^{\prime} 733,000$ & 24 & $24^{\circ} 028,000$ & 40 \\
\hline 1922 & $15^{\prime} 872,000$ & 21 & $14^{\prime} 037,000$ & 34 \\
\hline 1923 & $24^{\prime} 402,000$ & 24 & $19,776,000$ & 34 \\
\hline 1924 & $22^{\prime} 892,000$ & 22 & $23^{\circ} 837,000$ & 32 \\
\hline
\end{tabular}




\begin{tabular}{|c|c|c|c|c|}
\hline Año & $\begin{array}{c}\text { Exportación } \\
\text { del Peri } \\
\text { US }\end{array}$ & 8 & $\begin{array}{c}\text { Importación } \\
\text { del Perú } \\
\text { US } \$\end{array}$ & $\frac{g}{0}$ \\
\hline 1925 & $17^{\prime} 174,000$ & 19 & $23^{\circ} 032,000$ & 31 \\
\hline 1926 & $21^{\prime} 797,000$ & 24 & $29 \cdot 353,000$ & 40 \\
\hline 1927 & $20,091,000$ & 17 & $24: 870,000$ & 34 \\
\hline 1928 & $20^{i} 757,000$ & 16 & $23^{\prime}, 110,000$ & 33 \\
\hline 1929 & . $30 \div 167,000$ & 22 & $26^{\circ} 176,000$ & 34 \\
\hline 1930 & $21^{\prime} 284,000$ & 24 & $15^{\prime} 720,000$ & 30 \\
\hline 1931 & 81973,000 & 16 & 7935,000 & 27 \\
\hline 1932 & $3^{\circ} 685,000$ & 9 & $3^{\circ} 692,000$ & 24 \\
\hline 1933 & $5^{\prime} 472,000$ & 11 & $4^{\prime} 985,000$ & 24 \\
\hline 1934 & $6^{\prime} 191,000$ & 8 & $9^{\prime} 891,000$ & 25 \\
\hline 1935 & $77^{\circ} 462,000$ & 10 & $12^{8} 174,000$ & 28 \\
\hline 1936 & $9^{1} 023,000$ & 10 & $13: 439,000$ & 26 \\
\hline 1937 & $16 \cdot 525,000$ & 17 & $19 \cdot 016,000$ & 32 \\
\hline 1938 & $12^{\prime} 813,000$ & 16 & $16^{\prime} 893,000$ & 28 \\
\hline
\end{tabular}

FJERTE: Regort of the Secretary of State Trasi:itting a Statement from the Stperintendent of Statistic of the Conmercial Relations of the United States with Foreign Nations. Tashington, 18511914.

Aivance Sheets of Consular Reports. Washington $1901-02$.

Daily Consular and Trace Reports. Washington, 1903-14.

Conmerce Reports. Washington, 1915-31.

Report on the Finance, Industry and Trade of Peru.

London; 1022。

Latin American Section: Division of Regional Information, Bureau of Foreign Domestic Commerce. Waslington, diciembre 23, 1939. 
30 .

\section{CITAS}

1. Louis Cliniton Nolan, The Dinlomatic and Commercial Relations of the United States and Peru, 1826-1075, Duke liniversity, tesis inêdita, 1935 , p. 187.

2. Ibid.

3. "Letter of the Secretary of State Transmitting a Report on the Comner cial Relations of the United States with Foreign Countries for the Year Ended September 30th, $1862^{\prime \prime}$, Annual Report on Foreign Commerce, Washington, $186 \overline{3}, \mathrm{pp} .692-693$.

4. Louis Nolan, cp.cit. p. 188

5. Ibid, p. 216.

6. Ibid, p. 217 .

7. Ibid.

8. Denison Card to Secretary of State, Tumbes, September 1st., 1864, Microfilm publications, $T-353$, roll 1 .

9. "Letter of the Secretayy of State Transmitting a Report on the Comer cial Relations of the U.S. with Foreign Nations for the Year end -September 30, 1866" Annual Report on Foreign Commerce, Washington, 1867, p. 53.

10. Louis Nolan, op.cit., p. 224

11. Toid, pp. 226-227.

12. "Report of Consul Brent on the Commerce of Peri in 1884", Connercial Relations of the United States, part 2, 1884-1885, Washington, 1866 p. 798. 
13. "Perú Report of Consul Brent" , Cummercial Relations of the United -States with foreign Countries during the Year 1886 and 1887 , Washington, 1888, p. 689 .

14. Report Upon the Commercial Relations of the United States with -Foreign Countries for the Year 1880 and 1381, Washington, 1883, p. 118

15. Commercial Relations of the United States with Foreign Countries -during the year 1899, Washington, 1900, vol. I, p. 127.

16. "General Survey of Foreign Trade", Advance Sheets of Consular Reports, Washington, February 13th 1901, pp. 26-27 y "Peruvian American Trade" Ibid, n. 3076, Washington, Jamuary 17th, 1908, p. 5 .

17. William Bollinger, The Rise of United States Influence in the Peruvian Economy, 1869-1921, University of Califomic, Los Angeles, tesis inédi ta, 1972, p. 20.

18. Ibid, p. 53.

19. Tbid, p. 16.

20. Ibid, p. 20 .

21. "Perú Commercial Progress", Daily Consular and Trade Reports, Washington, April 24th 1906, no. 2546.

22. 'Perú's Commercial Progress", Daily Consular and Trade Reports, Washington, April 24th, 1906, no. 546, p. 6.

23. E. Hurley, Banking and Credit in Argentina, Brasil, Chile and Perú, Washington, 1914, pp. 66-69.

24. "Peruvian Exchange during the War", Cmamerce Reports, IIshington, January 17th, 1920, no. 14, p. 334. El tipo de cambio de la libra peruana fue equivalente a la libra esterlina y a 4.8665 ćslares. 
25. "Foreign Trade of Perü", Comerce Reports, January 12th, 1921, no. 9 p. 215.

26. "Trade of the West Coast of South America" , Conmerce Reports, Washing ton, June 16th, 1919, no. 140, p. 1393.

27. "Foreign Trade of Perip", Commerce Reports, Jamuary 12th, 1921, no. 9 , p. 215 .

28. "Peruvian Exchange during the War", Ibid, pp. 335-336.

29. Ib:d, sp. $356-337$.

30. Mici,, $3 j$.

31. Ibid, p. 339.

32. "Trade of the West Coast of South America", Ibid, p. 1390

33. Ibid, p. 1305

34. Ibid, p. 1396.

35. "Peruvian Govermment Seeking to Improve Economic Conditions", Comerce Reports, Washington, December 5th, 1921, p. 812.

36. "Perú: Exchange Situation", Commerce Reports, Washington, August 7th, 1922, p. 359 .

37. "Business Depression in Pera'" Comerce Reports, Washington, Jamuary 7th, 1224, p. 7; "Trade Continues Dull in Peru", Ibid, Washirigton, May 3 -d., 1926, p. 265; "Causes of the Exchange Slump in Perfi", Ibid Washington, November 1st., 1926, pp. 304-305.

38. I.G. Bertram, Development Droblens in an Export Economy: a Study of Domestic Capitalists, Foreign Finms and Government in Peru, 1919-1930, Oxford, tesis doctoral inédita, 1974, p. 31.

39. Ibid, p. 900

40. Ibid, pp. $27-50$.

41. William Bollinger, op.cit., p. 10 
42. Frederic M. Haisey, Investments in Latin America and the British West Indies, Washington, 1918, pp. 19 y 321-344.

43. William Bollinger, op.cit., pp. 10-11

44. I.G. Bertram, op.cit., p. 29.

45. James C. Carey, Perú and the United States 1900-1962, Indiana, 1964s pp. 54-55.

46. Hilliam Bollinger, cp.cit.s pp. 48-52.

47. Heraclio Bonilla, Gran Bretaña y el Perú, los mecanismos de un control económico, Lima, IEP, (en prensa).

48. I.G. Bertram, op.cit., p. 46.

49. James C. Carey, op.cit., p. 72.

50. I.G. Bertram, op.cit., p. 43. 
- PUBLICACIONES "CISEPA"

DEPARIARERTO DE ECONOMIA

\section{Libros}

ADOLFO FIGUEROA, Estructura del Consumo y Distribución de Ingresos en Lima Metropolitana, 1968-1969.

\section{Serie: Docunentos de Trabajo}

is I RTCHARD INEBB, "Informe sobre la Captaciốn de Recursos Financieros Adí cionales" por el Banco de Vivienda del Perú. (ASOTADO).

II 2 ALFRED H. SAULNIEIS, "Estinaciones de Activo Fijo e Inversiones: Sector Manufacturero". Setiembre, 1971. (AGOTADO):

I? 3 ALFRED H. SAULIIEPS, "Valor Ägregado e Inversión en el Sector Construcciơn" ${ }^{\text {" }}$. Setiembre, 1971. (AGOTADO).

IN 4 AXINO VEGA-CEVIENO, Mecanismos de Difusión del Conocimiento y Elección de Tecnologia". Yoviembre, 1971. Publicado en Comercio Exterior, Kéxico, Marzo, 1972. (A.GOIADO).

: 5 ADDIFO FIGUEROA, "Asignación de Recursos, Empleo y Distribuciốn de Ingreso en la Economía Peruana". Enero, 1972. (ASOTADO).

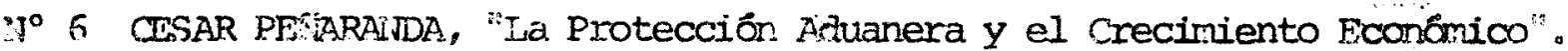
Setiembre, 1972 .

IT 7 MICHAEL THEMY, "Ensayo sobre la igricultura Peruana". Diciembre, 1972.

$M^{\circ}$ a ADOLFO FIGUEROA, "El Impacto de las Reformas Actuales sobre la Distribución de Ingresos en el Perú (1968-1972)". Julio, 1973. Publicado en $\mathrm{A}$. Foxley (ed.) Distribución de Ingresos (México: Fondo de Cultura Económica, 1974) $y$ en Apuntes (Iima) $1^{\circ} 1,1973$.

II 3 TAXIMO VEGA-CENTENO, "El Financiamiento de la Pequeña Industrie". Mayo, 1973.

MO IO CESAR PETAPANDA, "El Impacto de las Reformas Actuales sobre la Distribución de Ingresos en el Perü: Aspectos Adicionales y Comentarios". Enero, 1974. Publicado en Revista Apuntes (Limai Año $1_{i}$ तĩo 2,1974 ). 
$N^{\circ}$ Il OSCAR HILIONES D." "La Oferta de los Productos Agrícolas Alimenticios a la Zona Uruana". Marzo, 1973.

N० 12 ROBERRO ABUSADA-SALAH, "Propiedad Social: Algunas Consideraciones Economicas". Octubre, 1973. Publicado en Economic Analysis and Workers' Management (Belgrado), 1974.

$N^{\circ} 13$ LUISS PASARA, "Propiedad Social: La IJtopía y el Proyecto". Octubre, 1973. (AGOTADO) .

N. 14 CESAR PENARANDA, "Anteproyecto de Decreto Ley de la Propiedad Social: Co mentarios y Planteamientos Alternativos". Enero, 1971.

N 15 ADOLFO FIGUEROA, "Visión de las Pirämides Sociales: Distribución del In RICHARD IEISSKOFF greso en América Latina". Marzo, 1974. Publicado en Ensayos ECTEL (Rio de Janeiro: Año 1, NNo 1, 1974).

No 16 MAXIMO VEGA-CENIENO, "Tipo de Cambio, Paridades y Poder Adquisitivo en el. Grupo Andino". Mayo, 1974. Publicado en Ensayos ECIEL (Rio de Janeiro, Año 1, iNo 2, Julio, 1975).

iv 17 JORGE TORRes $z_{0}, "$ Análisis de la Estructura Econốmica de la Economla Peruana" : Payo, 1974.

$17^{\circ} .18$ RUFINO CFBRECOS, "Sistemas Tributarios y Competencia Comercial: Estudio ARMANDO ZOLEZZI del Grupo Andino". Mayo, 1974.

IN 19 MICHEL GIOSSUDOVSKY, "Hacia el Nuevo Modelo Económico Chileno-Inflación y Redistribuciốn del Ingreso (1973-1974)"。 Mayo, 1974.

$\mathrm{N}^{\circ} 20$ ARAANDO ZOLEZZI, "El Sistema Tributario Peruano". Mayo, 1974.

$\mathrm{N}^{\circ} 21$ PATRICIA WIISON, "Influencias Institucionales en el Desequilibrio Espacial del Perá: La Regionalización de las Inversiones Públicas". Julio, 1975. (AGOTADO)。

$N^{\circ} 22$ RUFLNO CEBRECOS, "El Empleo y el Desempleo en el Perún . Juiio, 1974.

NN 23 FOSER ARY THORP, "Industrializaciốn en una Economía Abierta: El Caso del GEOFF BEPTRA

NN 24 JAVIER IGUINIZ, "Algunas Tendencias en la Divisiôn Internacional del Trabajo". Albril, 1975.

$N^{\circ} 25$ JOSE Ma CABALLERO, "Aspectos Financieros en las Reformas Agrarias: Elementos Teóricos y Experiencias Históricas en el Perü". I layo, 1975.

No 26 MAXIMO VEGA-CENIERY, "El Desarrollo Econâmico del Perú y la Integración

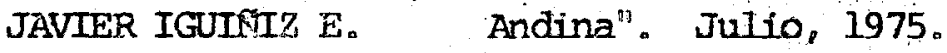


$N^{\circ} 27$ ADOLFO FIGUERA, "Estructura Social, Distribución de Ingresos e Integraciő́n Econơmica en el Grupo Andino:" Julio, 1975.

$\mathrm{N}^{\circ} 28$ HERACLTO BONILIA, "La Imergencia del Control Norteamericano sobre la ECO nomía Peruana: 1850-1930". Novienbre, 1975.

NN 29 CESAR PEITARANDA, "Integraciön Andina: Dimensionamiento del Mercado Subre gional y Distribuciôn de Ingresos. Febreco, 1376.

2⿰氵工 30 KENNETH JAMESON, "Industrialización Regional en el Peni". Abril, 1976.

$N^{\circ} 31$ FOBERTO ABUSADA-SALAH, "Utilización del Capital Instalado en el sector Industrial Peruano" Agosto, 1375.

IN 32 PATRICK SAINT POL, "La Inflaciốn en el Perú: Una Interpretaciớn". Setiembre, 1976.

iv 33 JORGE TORRES z., "Protecciones Efectivas y Sustitución de Importaciones en Perri". Diciembre, 1976.

Ho 34 JOSE M. CABALIERO, "Reforma y Peestructuración Agraria en el Peri". Diciembre, 1976. 


\section{Serie: Ensayos Tebricos}

IN 1 ADOLFO FIGUEROA, "Algunas inotas sobre la Teoría de la Producción". Setiembre, 1973.

$\mathbb{N}^{\circ} 2$ ROBERTO ABLXAADA-SAIAH, "Optima Utilización del Capital Instalado en EmPATRICIO IILIAN S. presas con Participación de los Trabajadores en la Gestion". "arzo, 1974.

IN 3 ITCHEL CHOSSUDOUSKY, "Anâlisis de Insumo Froducto". Setiembre, 1974. $\mathrm{N}^{\circ} 4$ JOSE 19. CABALLERO, "Notas sobre la Renta de la Tierra". Julio, 1975. NN 5 JAVIER IGUIinz, "La Crítica de Georgescu-Roegen a la TeorIa Económica". Julio, 1975.

I 6 ROBERTO ABUSADA-SALAH, "El Nivel de Utilización del Capital Instalado $y$ la Especificación de la Función de Producción". Agosto, 1976.

NN 7 JAVIER IGUIfIz, "Valor, Distribucion y Clases Sociales: Adam Smith, David Ricardo". Agosto, 1976.

\section{Serie: Coyuntura Economica}

iT 1 JAVIER IGUINIZ, Evolución de Algunos Indicadores Económicos 1968-1972". Llayo, 1975.

NN 2 JAVIER IGUUIILZ, "Desnutriciốn en Lima: 1971-1972". Junio, 1975. CARLOS PATARO 